\title{
Enzymatic pulp modification: an excellent way to expand the raw material base for Lyocell applications?
}

\author{
Birgit Kosan • Katrin Römhild • Frank Meister • Vincent Pelenc • \\ Stefan Kühnel $\cdot$ Matthias Gerhardt
}

Received: 17 December 2019/Accepted: 16 May 2020/Published online: 25 May 2020

(C) The Author(s) 2020

\begin{abstract}
The potential of enzymatic modification procedures was studied to adjust pulp properties for Lyocell process applications. Cellulases with welldefined activity compositions were identified and tested for pulp treatment. The changes of the pulp properties by such biotechnological modification were investigated especially concerning the resulting average degrees of polymerisation (DP) and the molecular weight distributions (MWD). Several industrial cellulases catalysed endo-splitting on solid cellulose. The selected compositions of the tested enzymes effected the intended decrease of the cellulose DP as suitable adaption of the MWD as well as an improvement of the pulp solubility in NMMO. The DP reduction of tested pulp qualities (paper, viscose and plant pulps) reached 20-35\% related to the DP of initial pulp. Depending on the used pulp quality, different changes of the molecular weight distributions with increase or decrease of the polydispersities were detected. Because of improved pulp solubility, spinning dopes with excellent solution qualities could be obtained, even when paper pulps with lower $\alpha$-cellulose were
\end{abstract}

B. Kosan $(\bowtie) \cdot$ K. Römhild · F. Meister

Thüringisches Institut für Textil- Und Kunststoff-

Forschung E.V, Breitscheidstr. 97, 07407 Rudolstadt,

Germany

e-mail: kosan@titk.de

V. Pelenc $\cdot$ S. Kühnel $\cdot$ M. Gerhardt

BioPract GmbH, Magnusstrasse 11, 12489 Berlin,

Germany applied. Exemplary, softwood TCF paper pulp was tested for upscaling in staple fibre. Also filament spinning could be successfully carried out. The prepared fibre samples showed good textile-physical properties. Enzymatic treatment could have a great potential for expansion of raw material base in Lyocell process. It could cause cost savings by applying cheaper cellulose pulps. It also provides options for use of alternative pulps from recycled textile fabrics or annual plants, outside of wood or cotton.

Keywords Enzymatic pulp modification · Cellulolytic activity $\cdot$ Lyocell process $\cdot$ Pulp base expansion · DP adaption - Solution state

\section{Introduction}

The demand for fibrous materials in textile and technical applications shows above-average growth rates since some years. For example, the global fibre demand is expected to increase from 87 million tons in the year 2014 to 240 million tons in 2050 (Björquist et al. 2017), whereby the 100 million tons limit has already been exceeded in 2016 (Wollenschlaeger 2017). This predicted, disproportionately high increase of the fibre demand is neither feasible by appropriate improvement of the production of synthetic fibres due to their different moisture management nor by a further increase of the cotton 
production, because of limitation of the cultivated grounds in favour of also increasing world food demand as well as comparatively unfavourable farming requirements, i.e. high water consumption, usage of genetically modified seeds and pesticides in cotton cultivation (Gherzi 2011). The resulting, unfulfilled demand is referred to as "cellulose gap" (Hämmerle 2011; Eichinger 2012). In addition, more and more consumers demand more sustainable products. This competitive situation opens up the possibility, but also the necessity.

- for a significant improvement of the capacities for production of cellulosic man-made fibres,

- for selection of most favourable, environmentally friendly fibre spinning processes and

- for supply of required, high purity dissolving pulp amounts.

The direct dissolution process of cellulose in $\mathrm{N}$-methylmorpholine-N-oxide monohydrate (NMMO) combined with dry-wet fibre spinning, which is called Lyocell process, is well developed as a very environmentally friendly technology for production of cellulosic regenerated fibres (Harms 2002). The process technology is established at industrial scale and the non-toxic solvent used is performed in a nearly completely closed circuit (Kalt and Zauner 2001).

However, the Lyocell processing requires the use of highly purified dissolving pulp qualities with welldefined average degree of polymerisation (DP), low organic and low inorganic impurities, which were all directly adapted for the process.

For further increase of produced fibre amounts, an extension of the range of cellulosic raw materials for applications in Lyocell fibre spinning would be of greatest interest. The utilization of additional pulp qualities, as for instance modified, but little cheaper paper grade pulps, dissolving pulps made of annual plants (Paulitz et al. 2017) or fibre raw material from recycled textile fabrics is a promising approach either to cover the expected increase in raw materials needs or from the point of view of developing a circular flow economy.

For all the named sources pulps have to be adjusted to the Lyocell process requirements. That means, amount of organic impurities like lignin and hemicelluloses have to be minimised to a process conform scale. Furthermore, inorganic impurities like iron or copper salt concentrations should have to be degraded down to $10 \mathrm{ppm}$ level. The same is valid for earth alkali salt concentration. The acceptable amount of magnesium and calcium salts should have to be limited to lower hundreds of ppm.

Finally, the pulp DP should be adjusted to level of 550 to 650 . For that purpose the use of enzymatic pulp modification processes could be a very interesting option.

Cellulases with different activities, for example endo and/or exo-activities are of great relevance as suitable enzyme systems for the intended cellulose modification. Endoglucanases can split cellulosic material at random in the core of the cellulose polymer. They mainly act on the amorphous part of the cellulose. Cellobiohydrolases are exoglucanases which release cellobiose units from the chain ends of the cellulose, also in crystalline regions, whereas further the cellobiose can be split to mono sugars by 1,4- $\beta$-glucosidases (Suurnäkki 2000). Possibilities of enzymatic pulp treatment were also discussed for usage in different cellulose shaping processes beside Lyocell applications. For example, the treatment of dissolving pulps using monocomponent endoglucanase preparations was investigated with regard to an influence on the pulp reactivity in the Viscose process (Östberg and Germgard 2013). Using aqueous caustic soda process media for direct cellulose dissolution (Biocelsol process), combinations between intensive mechanical shredding and enzymatic pulp treatment using endoglucanase rich enzyme preparations were described for significant reduction of the pulp DP and improvement of cellulose solubility. (Grönqvist et al. 2015; Vehviläinen et al. 2015).

For application in Lyocell fibre manufacturing, the use of enzyme preparations with exo-activities is already known to improve the cellulose accessibility at direct dissolution in NMMO (Meister et al. 1996) preferably without significant DP reduction.

For the usage of new, alternative cellulose sources for Lyocell applications, beside an improvement of the cellulose accessibility also an adaption of the DP and the molecular weight distribution of the cellulose to the Lyocell requirements is necessary.

It is the target of the paper to report on the technological and analytical approaches available to assess dissolving pulps manufactured from alternative pulp sources. It would like to highlight the possibilities of a specific adjusted enzymatically modification of 
these different pulps to become suitable in the Lyocell process. Furthermore the paper will demonstrate and discuss the application of suitable cellulase mixtures with adjusted ratios of exo- and endo-activities for improvement of the accessibility of the cellulose molecules and targeted reduction of their long-chain cellulose fraction, respectively.

\section{Experimental}

\section{Materials}

The investigations were carried out using pulp samples from different proveniences, softwood TCF pulp (NH-P, paper pulp quality), viscose pulp (VZ, i.e. for tire cord production) and hemp pulp (HP, special test batch). For comparison, spruce / pine dissolving pulp sample (Lyocell pulp sample, LYO) was included. The most important analytical parameters of the pulps are summarised in Table 1.

In this study, a collection of 70 ligno-cellulolytic enzyme preparations was examined. The preparations were commercially available industrial enzymes in form of amber coloured liquids or solid-formulated powders. This collection represented a variety of microbial origins (more than 10 different production strains, mainly fungi), industrial origins (more than 8 producers and production processes) as well as several application fields (textile, laundry, feed, biomass deconstruction for bioenergy).

N-Methylmorpholine-N-oxide was used as 50\% aqueous solution, delivered from BASF, without any further pre-treatment.

Dimethylacetamide was used in HPLC grade. All other used chemicals were obtained in analytical grade, respectively and were used without any further pre-treatment.

\section{Enzymatic pulp treatment}

The enzymatic treatment of the pulp samples was separately carried out before the pulp was admixed to the aqueous NMMO solution and could be smoothly integrated into the existing NMMO technology.

The treatment procedure took place in aqueous medium using enzyme concentrations between 0.3 and $1 \%(\mathrm{w} / \mathrm{w})$, referred to cellulose, at $\mathrm{pH}$ of 5.5 during 60 min treatment time at $50{ }^{\circ} \mathrm{C}$. The treatment was stopped by $\mathrm{pH}$ increase up to 9 . Following, the treated pulp was pressed out from the excess water down to about $30 \%$ solids content and introduced in aqueous NMMO for further processing.

For analytical characterisation, the treated pulp samples were washed by deionised water up to neutral $\mathrm{pH}$, pressed out from the excess water and air dried. The pulp yield after enzymatic treatment, calculated from the pulp losses of the samples for analytical characterisation after washing and filtration steps, was between 86 and $92 \%$, depending on the used pulp and enzyme samples. The pulp losses, calculated from oxidable sugar contents of the press water samples were between 0.2 and $2.2 \%$. Thus, the upscaling and integration into the Lyocell processing should be result in higher pulp yields of the enzymatic modification step.

Preparation of cellulose solutions

The preparation of cellulose dopes was carried out using laboratory vertical kneader system, linked with a RHEOCORD 9000 (HAAKE). Temperature, torque moment and revolutions per minute (rpm) vs. time were recorded on-line. The dopes were prepared, starting from an aqueous suspension of the treated pulp in 50\% aqueous NMMO, by removal of the excess water at elevated temperatures, higher shearing stress and low pressure during the dissolution processes $\left(80-95{ }^{\circ} \mathrm{C}\right.$ mass temperature, 800-40 mbar pressure, $5-20 \mathrm{rpm})$. Propylgallate $(0.5 \% \mathrm{w} / \mathrm{w}$ with
Table 1 Analytical data of the used pulp samples

\begin{tabular}{lllll}
\hline Pulp sample & NH-P & VZ & HP & LYO \\
\hline Cuoxam-DP & 763 & 838 & 656 & 590 \\
$\alpha$-cellulose content $(\%)$ & 85.5 & 98.0 & 96.1 & 92.9 \\
Content of carboxyl groups $(\mu \mathrm{mol} / \mathrm{g})$ & 33.2 & 16.9 & 20.7 & 10.4 \\
Content of carbonyl groups $(\mu \mathrm{mol} / \mathrm{g})$ & 27.6 & 10.2 & 14.3 & 42.3 \\
\hline
\end{tabular}


regard to cellulose) was used for stabilisation of the NMMO solutions. After the finishing of water removal (achieving a NMMO monohydrate state), an afterdissolution step $\left(60 \mathrm{~min}, 90{ }^{\circ} \mathrm{C}\right.$ mass temperature, 250 mbar) followed for homogenisation of the prepared dope.

A first upscaling in $4 \mathrm{~kg}$ dope scale was carried out using planetary mixing machine PML 40 (NetzschFeinmahltechnik GmbH).

\section{Spinning trials}

First spinning tests were carried out by dry-wet spinning experiments for preparation of staple fibres of about 1.7 dtex fineness using a laboratory piston spinning equipment, which is described in former publication (Kosan et al. 2008). Spinning nozzles, containing 30 holes with capillary diameters of $100 \mu \mathrm{m}$ were used for all laboratory spinning experiments. The spinning temperatures were selected in each case according to the rheological properties of the used cellulose dopes.

Further semi-technical spinning tests using spinnerets with $6 \times 80$ capillaries ( $90 \mu \mathrm{m}$ outlet diameter) were carried out for investigation of the spinning behaviour and stability. These trials were used for preparation of staple fibres and multifilament samples.

\section{Methods}

Cellulose characterisation

The virgin and the enzymatically treated pulp samples as well as the cellulose samples regenerated from the dopes and from the spinning tests, all dissolved in Cuoxam solution, were characterised by capillary viscosity for determination of the average degree of polymerisation (Cuoxam-DP) using an internal institute standard. For this purpose, the intrinsic viscosity $[\eta]_{\text {Cuoxam }}(\mathrm{ml} / \mathrm{g})$ was detected by means of an automatic capillary viscometer measurement (SCHOTT AVS 360). The Cuoxam-DP was calculated according to the Eq. (1).

Cuoxam-DP $=2 \cdot[\eta]_{\text {Cuoxam }}$

The method was described by Klemm et al. (1998).
The molecular weight distributions of the cellulose samples were determined by SEC analysis in the solvent dimethylacetamide (DMAc)/LiCl using a triple detection size exclusion chromatography system (SEC, Viscotek, USA). The samples were dissolved in $\mathrm{DMAc} / \mathrm{LiCl}$ after a solvent exchange procedure from water to Acetone and then to DMAc. The details of the equipment configuration were described in former publication (Kosan et al. 2012). In the case of cellulose samples with $\alpha$-cellulose contents $<90 \%$, the sample preparation was carried out following Berthold et al. (2001).

Alpha-cellulose content was determined as such a part of pulp that is not dissolvable in a $17.5 \mathrm{wt} \%$ aqueous sodium hydroxide solution at $20{ }^{\circ} \mathrm{C}$.

Analytical determination of the carboxyl group content was carried out by a complexometric titration of zinc ions after removing the metal ions from the cellulose and subsequent addition of zinc acetate solution.

The carbonyl group content was analysed by measurement of the absorbency at $530 \mathrm{~nm}$ after chemical reaction with 2, 3, 5-triphenyltetrazoliumchloride solution.

The details of this cellulose characterisation were described in former publications (Kosan et al. 2012; Meister and Kosan 2015).

\section{Enzyme characterisation}

To compare and select the enzyme preparations in objective manner, all enzymes of the collection were characterized by measuring enzyme activities relevant in the context of cell wall degradation. Standard colorimetric biochemical methods were applied.

Filter paper activity was measured using filter paper as substrate and expressed as Filter Paper Units (FPU) according to Ghose (1987). FPU mainly represent the combined activity of cellobiohydrolases, which release cellobiose from the ends of insoluble cellulose chains by exo-mechanism of action, and B-glucosidases, which release glucose from cellobiose.

Enzyme activities toward soluble plant cell wall polysaccharides were determined according to König et al. (2002), using soluble polymeric model substrates (Table 2). Mainly endo-enzymes were detected using these substrates. These enzymes split polysaccharide chains within their core. 
Table 2 Enzyme activities toward soluble, plant-derived model substrates

\begin{tabular}{llll}
\hline Activity & Substrate & Additional information & Supplier \\
\hline Cellulase & Carboxymethyl cellulose (CMC) & Ultra-low viscosity & Fluka \\
$\beta$-Glucanase & Lichenan (mixed-linkage $\beta$-glucan) & Icelandic moss & Megazyme \\
Xylanase & Wheat arabinoxylan & Medium viscosity & Megazyme \\
Pectinase & Citrus peel pectin & Unsaponified, degree of methyl-esterification $<50$ & CP Kelko \\
\hline
\end{tabular}

Briefly, activity measurements consisted in (1) enzymatic hydrolysis step by incubating substrate (filter paper resp. polysaccharide in solution) together with enzyme solution in buffer and (2) stop/detection step by adding alkaline 3,5-dinitrosalicylic acid reagent and heating. In the first step the enzymes split the polysaccharides and produced reducing carbonyl groups. In the second step the reagent was reduced to 3-amino-5-nitrosalicylic acid which exhibited redorange colour proportionally to the enzymatic reaction extent.

Industrial enzymes are produced in a fermentation process as complexes of numerous principal and secondary hydrolytic proteins. The natural polysaccharide substrates were split by several proteins present in the preparations. Furthermore, single hydrolytic proteins may have split several of the chosen substrates. Mainly $\beta$-1,4-endo-glucanases (EC 3.2.1.4), $\beta-1,3 / 1,4$-mixed-linkage-glucanases, $\beta-1,4$ xylanases and $\alpha$-1,4-galacturonidases were detected in the chosen set of measurements.

Enzyme activity unit (U) was defined as the amount of enzyme that releases $1 \mu \mathrm{mol}$ of reducing equivalents per minute under the assay conditions using glucose or xylose as reducing sugar standard.

For the measurement of endo-activity on solid cellulose, no standard biochemical method was available. Therefore, application tests for enzymatic treatment of highly purified cellulose (chromatographic paper) in aqueous medium were used for investigation of the potential for DP reduction. The Cuoxam-DP values of the treated cellulose were compared with the initial DP of the chromatographic paper and the percentage DP reduction determined.

The tests were carried out using different enzyme concentrations between 0.3 and $4 \%(w / w)$, referred to cellulose, at variation of the $\mathrm{pH}$ between 4.5 and 6.5, treatment times between 60 and $120 \mathrm{~min}$ and treatment temperatures between 50 and $65{ }^{\circ} \mathrm{C}$. The enzymatic treatment was stopped by increase of the $\mathrm{pH}$ up to 9. Following the cellulose was washed, airdried and the Cuoxam-DP of the enzymatic treated cellulose was determined.

Analytical characterisation of cellulose solutions

Optical characterisation of cellulose solutions was carried out by means of polarisation microscopy (ZEISS Axiolab). Furthermore, measurements by laser diffraction (HELOS particle size equipment, SYMPATEC) were used for determination of the particle distribution and particle content of prepared spinning dopes (Kosan and Michels 1999).

The determination of the solids contents in the solutions was performed by means of weighing precipitated films, after exhaustive solvent extraction and drying.

The rheological characterisation of cellulose solutions was performed using a rheometer HAAKE MARS with cone/plate measuring system $\left(4^{\circ}\right.$ angle geometry) and electrically heated cone $\&$ plate unit with active cone heater.

Zero shear viscosities were calculated from creep attempts in the rotation mode at shear stress of $90 \mathrm{~Pa}$. The determined cellulose solutions showed significant viscoelastic behaviour. A characterisation of the viscoelastic properties was realised in the oscillation mode. Oscillation tests were carried out as frequency sweeps (0.046-14.7 Hz, deformation: 0.07) at different temperatures $\left(60 / 85 / 110^{\circ} \mathrm{C}\right)$. WLF-transformation was used for calculation of master curves and relaxation spectra at $85^{\circ} \mathrm{C}$ reference temperature. This method permits an interpolation of the frequency/ angular rate range over several decades and is an evaluated method for the determination of viscoelastic properties of polymer solutions. Details of the 
rheological dope characterisation were described in former publications (Michels and Kosan 2003; Meister and Kosan 2015).

\section{Fibre characterisation}

The textile-physical fibre parameters were determined according to the following methods:

- fineness according to DIN EN ISO 1973,

- tenacity and elongation at break according to DIN EN ISO 5079 and

- loop tenacity according to DIN 53,843, part 2.

The filament samples were tested according to:

- yarn fineness according to DIN EN ISO 2060 and

- maximum tensile strength and elongation according to DIN EN ISO 2062.

The water retention values (WRV) were determined according to DIN 53,814.

\section{Results and discussion}

Selection and pre-testing of enzymes

The goal of enzyme pre-selection was to set up an objective variety of 10 to 20 preparations for functional application pre-testing (DP reduction test). This aimed at high opportunity of finding suitable preparations within a reasonable number of application pretests. On the basis of their enzyme activities, the preparations of the collection were classified in 9 activity profiles. The profiles were very distinct from each other and contained 5-10 preparations with similar ratios of activities. The targeted diversity of preparations was sufficient and adequate.

A subset of 19 preparations was thus chosen in different profiles and from various microbial and industrial origins. When tested towards chromatographic paper, the studied enzyme preparations reduced the DP from $0 \%$ to $27.4 \%$. Seven preparations produced a DP-reduction of more than $21 \%$. Three of them were active at low to moderate dosage $(0.3 \%-$ $1 \%)$. From the application pre-tests results, availability and diversity, the enzyme samples P4, P10 and P11 were chosen for application tests of enzymatic pulp modification. The activities of these preparations as well as their performance in application pre-tests are presented in Table 3.

Protein content was highest for P4, middle for P10 and lowest for P11. CMCase and B-glucanase varied in the same way. Xylanase was highest in P10. Pectinase was low for all selected samples. Remarkably, no FPU was detectable in P11 even though this preparation displayed the highest DP reduction.

The preparations P4, P10 and P11 were compared to the pre-selected samples using their ranks of protein specific activities within the complete collection. Ranks ranged in the same interval for all activities and were thus more convenient than activities for comparison. Specific activity ranks were displayed in 5-ray spider charts, where each ray represented the activity rank for FPU, CMCase, $\beta$-glucanase, xylanase and pectinase, respectively (Fig. 1). With each preparation represented by a pentagon, the shape of the pentagon was used to classify the preparations in different categories (Fig. 1b-f).

In Fig. 1a, the selected preparations P4, P10 and P11 were displayed. In many cases, similar enzymatic activities combinations corresponded to similar DP reduction performance. Three preparations similar to $\mathrm{P} 4$ (Fig. 1b) performed at middle level in the range [17-18\%]. In the category of P11 (Fig. 1c) characterized by undetectable FPU and pectinase, three preparations performed in the range [23-25\%]. In this group, P13 yielded only 10\% DP-reduction. This preparation was produced by a bacterium for brewery applications. P14 displayed a similar profile to P10 (Fig. 1d) but produced a DP-reduction of only $11 \%$. In Fig. 1e three preparations focusing on Xylanase/ CMCase were displayed. In this group, performance correlated to beta-glucanase (P17: 22\%; P2: 17\%; P20: 0\%). Further preparations tested performed poorly or not at all (Fig. 1f, P5: 15\%; P8: 12\%; P16: $0 \%$, further not shown).

From these observations of biochemical and functional tests, trends could be derived. DP reduction was performed by preparations displaying diverse enzymatic activity combinations. The presence of FPU was not necessary for DP-reduction. Xylanase activity was not sufficient. Presence of beta-glucanase activity was a good indicator for DP-reduction performance, but not sufficient.

The DP reduction from solid cellulose may be performed by catalytic proteins which are partially detected by standard biochemical measurement using 
Table 3 Enzymatic properties and DP reduction of selected preparations - Enzyme dosage for DP-reduction $=$ P4: $0.3 \%$, P10 and P11: $1 \%$

\begin{tabular}{lcrlccrc}
\hline & Protein $(\mathrm{mg} / \mathrm{g})$ & FPU $(\mathrm{U} / \mathrm{g})$ & CMCase $(\mathrm{U} / \mathrm{g})$ & B-Glucan-ase $(\mathrm{U} / \mathrm{g})$ & Xylanase $(\mathrm{U} / \mathrm{g})$ & Pectinase $(\mathrm{U} / \mathrm{g})$ & DP red $(\%)$ \\
\hline P4 & 261 & 107 & 9578 & 13,910 & 934 & 15 & 21 \\
P10 & 155 & 51 & 5052 & 5510 & 10,760 & 436 & 25 \\
P11 & 70 & 0 & 1046 & 1909 & 319 & 0 & 27 \\
\hline
\end{tabular}

beta-glucan soluble substrate. This assessment is suitable for the detection of endo-glucanase activities as a sum. The example of P11 which performs best with poor specific activities suggests that this measurement is not specific for DP reduction activity. The active proteins performing DP reduction may belong to further categories not assessed in this study. Indeed, even after decades of investigations, cellulase research is still in progress (Kostylev and Wilson 2012). In recent years, new classes of cellulases enzymes were discovered. For example, Vermaas et al. (2015) reported the discovery of a new class of enzymes that utilize an oxidative mechanism to cleave glycosidic linkages called lytic polysaccharide monooxygenases (LPMO). As far as known by the authors, such activities are not available at industrial scale. A sensitive, specific and miniaturized test for DP reduction would help in developing a molecular approach of this process, necessary for the directed development of cellulase complexes with better performance.

Investigations for enzymatic treatment of NH-P pulp sample and following dissolution and spinning tests

\section{Enzymatic modification of the pulp sample NH-P}

Because of its very wide molecular weight distribution (MWD) containing very high molecular cellulose parts, a direct usage of the paper pulp sample NH-P for Lyocell applications is not possible. The solubility as well as the accessibility of the pulp sample for the process solvent NMMO is too low to achieve acceptable solution states for dry-wet spinning to cellulose fibres. Enzymatic treatments were carried out using $0.3 \%$ enzyme sample P4, $1 \%$ P10 as well as $1 \%$ P11. This enzymatic pulp modification resulted in a suitable reduction of the Cuoxam-DP of the pulp sample and especially in a significant decrease of the polydispersity of the modified pulp samples. The results from SEC characterisation and the measured Cuoxam-DP of the modified samples in comparison to the starting NH-P pulp sample as well as to the Lyocell pulp sample LYO are listed in Table 4. Figure 2 contains the graph with the MWD of the samples.

The starting pulp sample NH-P is characterised by bimodal MWD. The determined polydispersity was very high (Mw/Mn: 12.1). The enzymatic treatment resulted in significant decrease of the polydispersities of the modified pulp samples (Mw/Mn: 4.4-4.7). The MWD of all three enzymatic treated samples are very similar and equivalent to the comparative LYO pulp sample. The weight average molecular weights $\mathrm{Mw}$ and $\mathrm{z}$-average molecular weights $\mathrm{Mz}$ of the pulp samples were more than halved by the enzymatic procedure. By contrast, the number average molecular weight $\mathrm{Mn}$ of the enzymatic treated samples was similar or slightly increased compared to the initial pulp sample. The attained Cuoxam-DP values of the modified pulp samples were between 590 and 619, in an appropriate area for the preparation of Lyocell fibres.

\section{Comparative dissolution and spinning tests using} starting and enzymatic modified NH-P pulp samples

Dissolution tests in NMMO using the starting pulp sample NH-P did not permit the preparation of spinning dope with acceptable dope qualities. Using reduced cellulose concentration of $9 \%(w / w)$, the unmodified pulp sample resulted in a very bad solution state, containing a lot of undissolved fibre fragments (Fig. 3, left). Contrary to this, the enzymatic modified pulp samples could be used for dope preparation in laboratory scale with cellulose concentrations between 12 and $12.5 \%$ (w/w). The microscopic images of the prepared dopes showed strongly improved solution states without any undissolved fibre residuals 


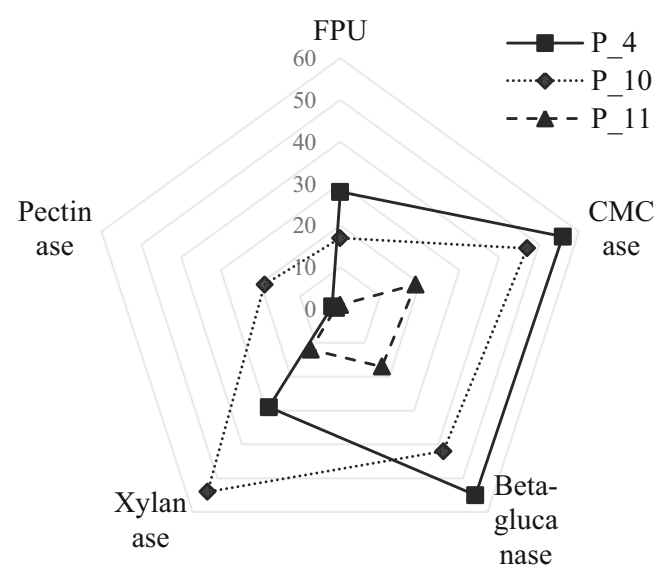

(a) selected preparations

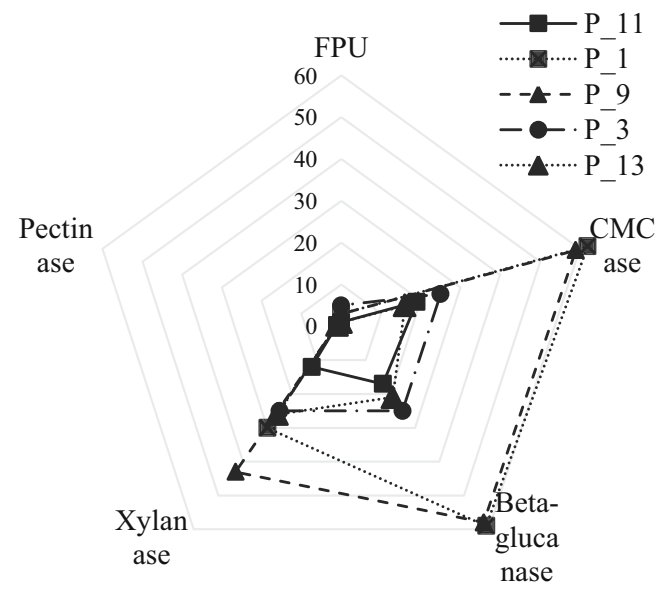

(c) similar to P11

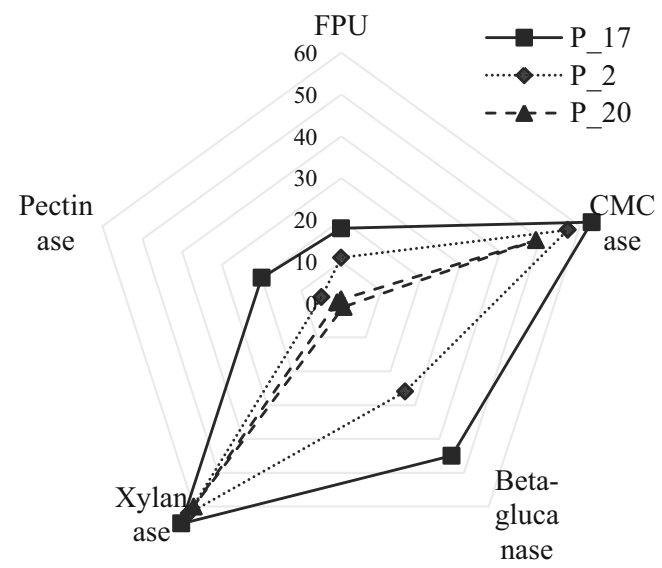

(e) xylanase focussed

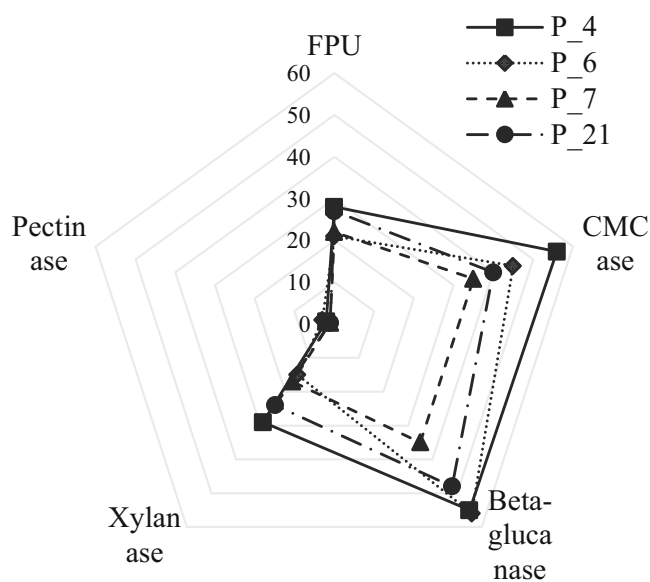

(b) similar to P4

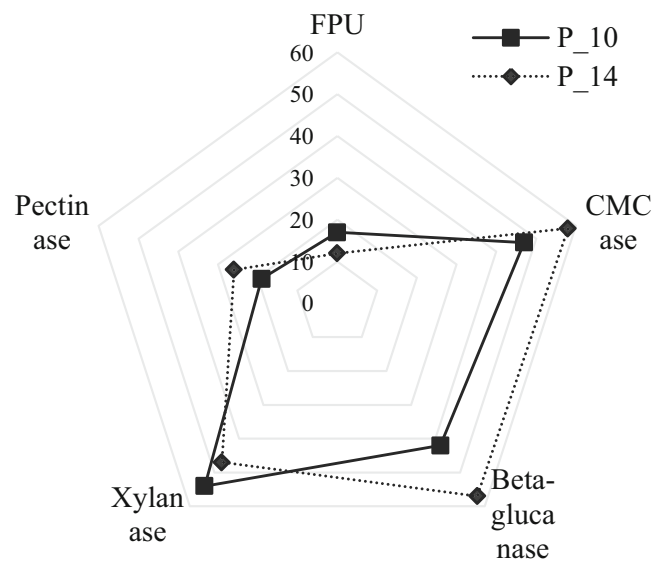

(d) similar to P10

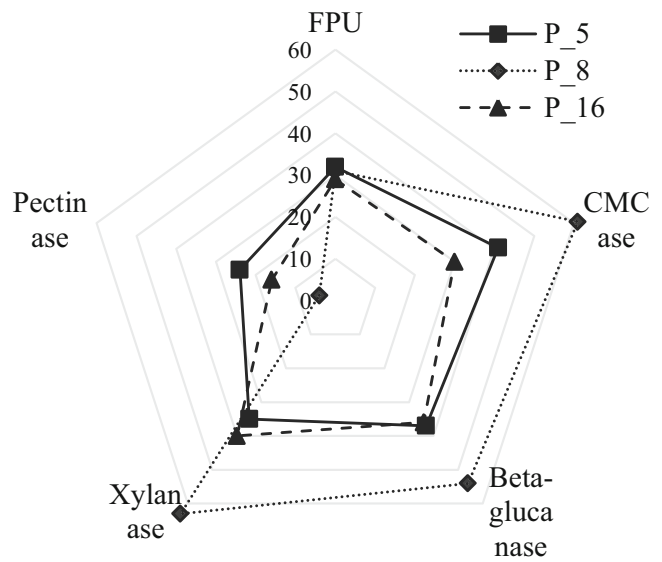

(f) further preparations

Fig. 1 Activity profiles of selected preparations P4, P10 and P11 in comparison to the pre-selected preparations 
Table 4 Results of SEC analysis and Cuoxam-DP of starting and modified NH-P pulp samples

\begin{tabular}{llllll}
\hline Sample & Mn (daltons) & Mw (daltons) & Mz (daltons) & Mw/Mn & Cuoxam-DP \\
\hline NH-P (starting pulp) & 53,484 & 648,935 & $1,853,256$ & 12.1 & 763 \\
NH-P (P4 treated) & 57,475 & 269,964 & 854,172 & 4.7 & 619 \\
NH-P (P10 treated) & 59,048 & 258,322 & 815,545 & 4.4 & 612 \\
NH-P (P11 treated) & 63,768 & 277,663 & 876,557 & 4.4 & 590 \\
LYO & 49,938 & 270,916 & 809,647 & 5.4 & 590 \\
\hline
\end{tabular}

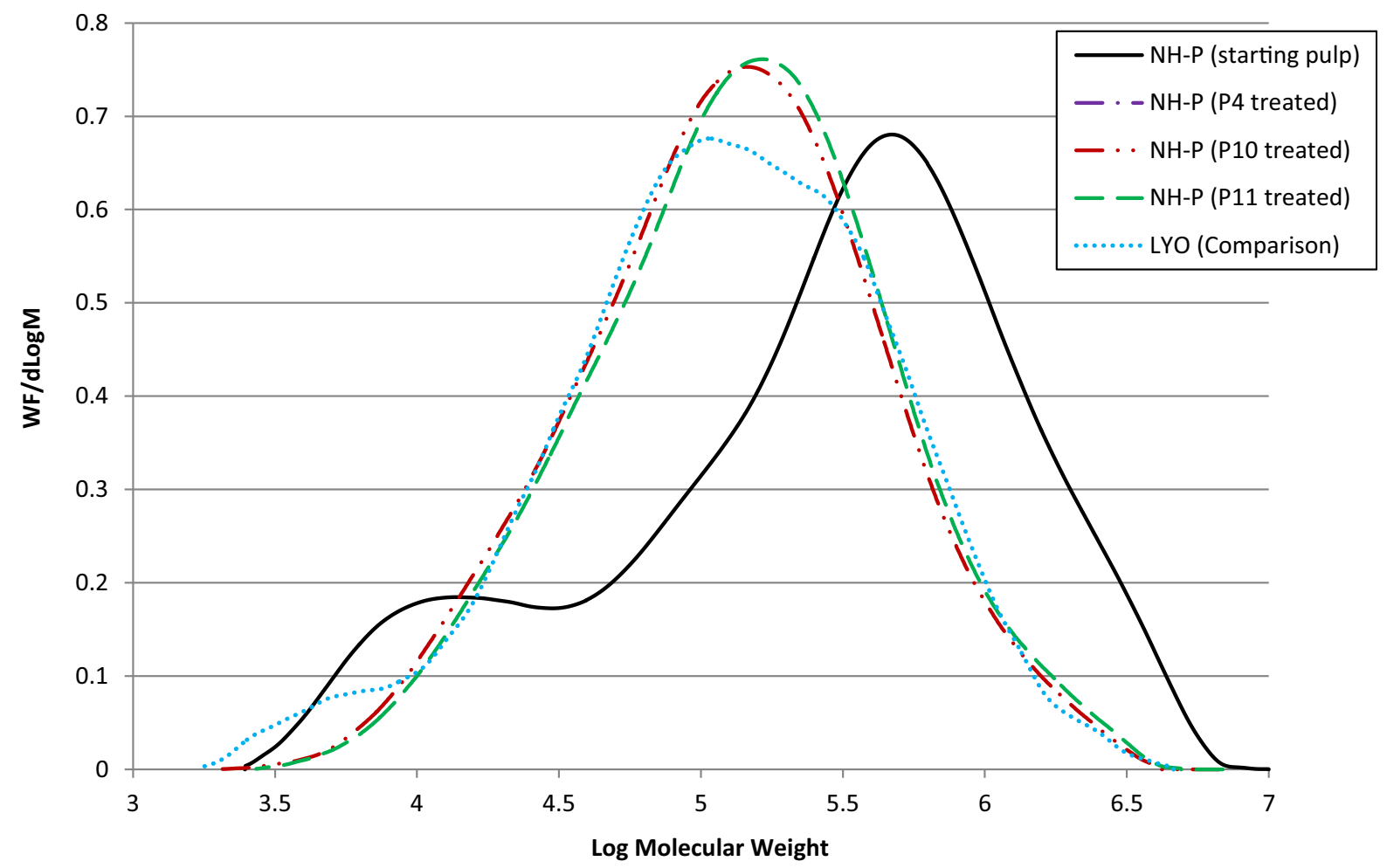

Fig. 2 MWD of starting and modified NH-P pulp samples in comparison to the LYO pulp sample

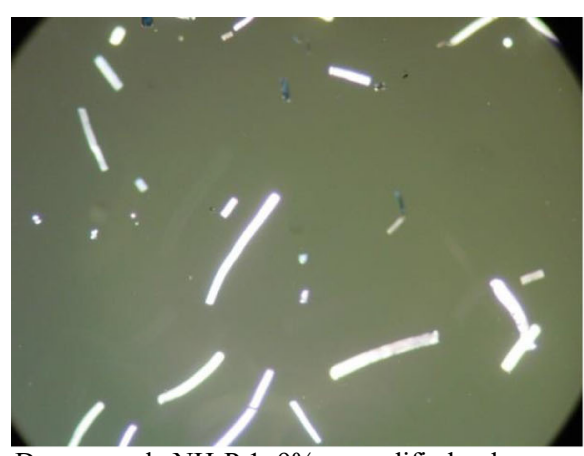

Dope sample NH-P 1: 9\% unmodified pulp

NH-P in NMMO

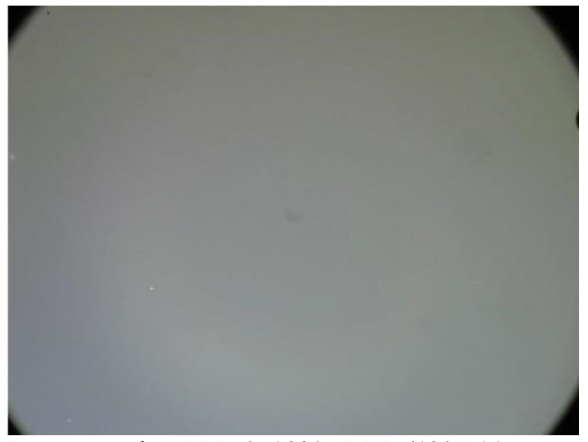

Dope sample NH-P 4: 12\% NH-P (1\% P11

modified) in NMMO

Fig. 3 Microscopic images of prepared spinning dopes in NMMO (transmitted light, polarization microscopy, 10x-objective) 
Table 5 Spinning

conditions and achieved fibre properties using pulp sample NH-P

\begin{tabular}{|c|c|c|c|c|c|}
\hline Sample & & NH-P 1 & NH-P 2 & NH-P 3 & NH-P 4 \\
\hline Pulp treatment & & Without & $0.3 \% \mathrm{P} 4$ & $1 \%$ P10 & $1 \% \mathrm{P} 11$ \\
\hline Cuoxam-DP of applied pulp sample & & 763 & 619 & 612 & 590 \\
\hline Dope zero shear viscosity $\left(85^{\circ} \mathrm{C}\right)$ & Pas & 7295 & 12,130 & 11,570 & 9587 \\
\hline \multicolumn{6}{|l|}{ Spinning conditions } \\
\hline Spinning temperature & ${ }^{\circ} \mathrm{C}$ & 87 & 89 & 89 & 87 \\
\hline Spinning pressure & Bar & $32-38$ & 29 & 33 & 23 \\
\hline Spinning behaviour & & Unstable & Stable & Stable & Stable \\
\hline \multicolumn{6}{|l|}{ Fibre testing } \\
\hline Fineness & dtex & 1.81 & 1.75 & 1.79 & 1.40 \\
\hline Tenacity, cond & $\mathrm{cN} /$ tex & 30.8 & 35.4 & 34.2 & 33.8 \\
\hline Elongation, cond & $\%$ & 12.2 & 14.4 & 13.3 & 13.5 \\
\hline Loop tenacity & $\mathrm{cN} /$ tex & 14.7 & 14.7 & 17.3 & 16.0 \\
\hline E-modulus $0.5-0.7 \%$ & $\mathrm{cN} / \mathrm{tex}$ & 795 & 922 & 882 & 855 \\
\hline Water retention value (WRV) & $\%$ & 95.6 & 87.4 & 91.7 & 82.6 \\
\hline Cuoxam-DP fibre & & 703 & 567 & 560 & 545 \\
\hline \multicolumn{6}{|l|}{ SEC characterisation of fibres } \\
\hline $\mathrm{Mn}$ & Daltons & 74,503 & 55,916 & 56,679 & 55,453 \\
\hline Mw & Daltons & 244,675 & 200,467 & 191,544 & 189,334 \\
\hline $\mathrm{Mz}$ & Daltons & 616,124 & 532,080 & 477,368 & 461,425 \\
\hline Mw/Mn & & 3.3 & 3.6 & 3.4 & 3.4 \\
\hline
\end{tabular}

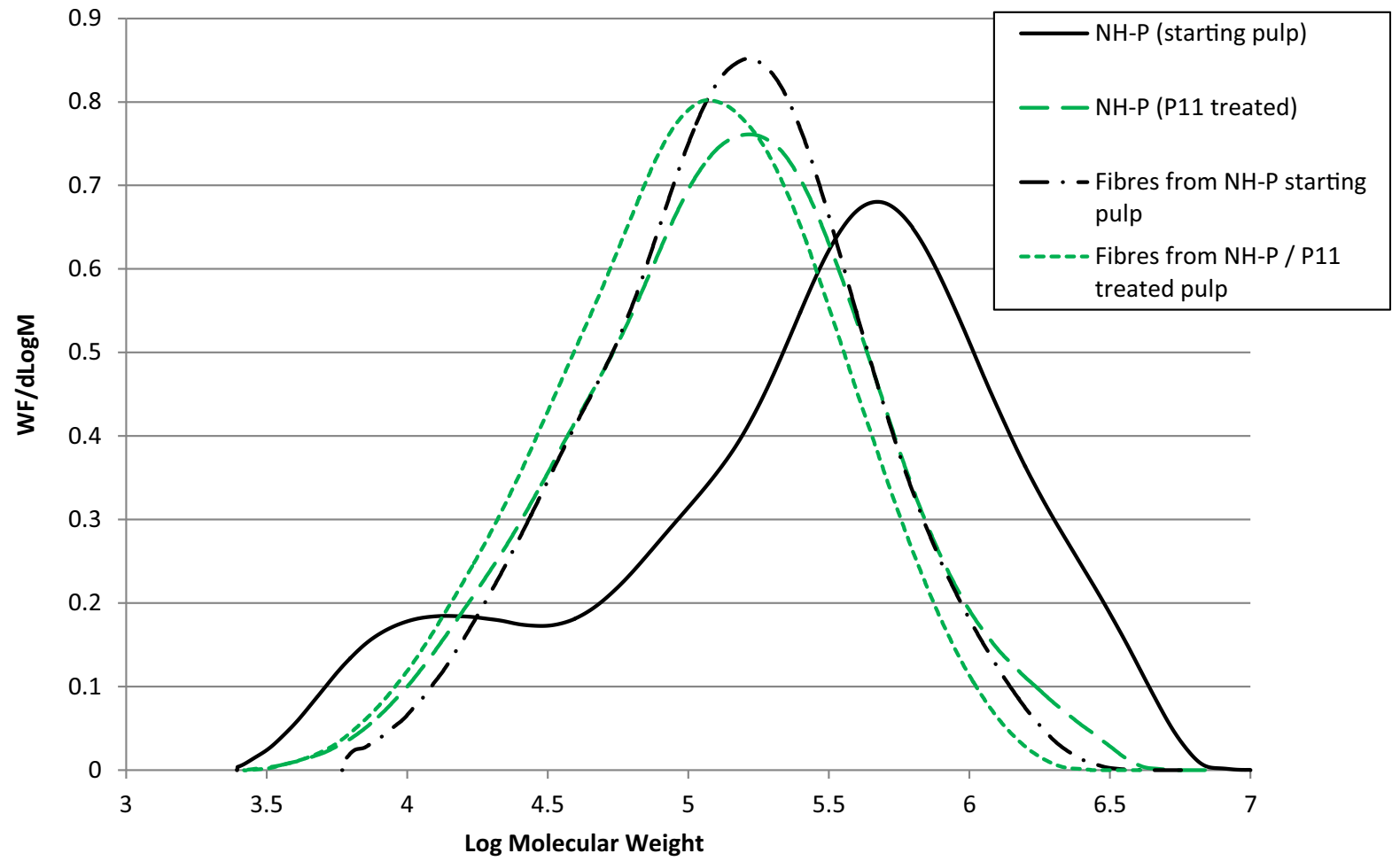

Fig. 4 MWD of starting and modified NH-P pulp samples in comparison to fibres spun thereof 
Table 6 Results of SEC analysis and Cuoxam-DP of starting and modified VZ and HP pulp samples

\begin{tabular}{lcllll}
\hline Sample & Mn (daltons) & Mw (daltons) & Mz (daltons) & Mw/Mn & Cuoxam-DP \\
\hline VZ (starting pulp) & 156,348 & 369,152 & 682,318 & 2.4 & 838 \\
VZ (P4 treated) & 72,992 & 296,514 & 642,435 & 4.1 & 693 \\
VZ (P10 treated) & 69,585 & 254,321 & 609,552 & 3.7 & 608 \\
VZ (P11 treated) & 44,311 & 213,767 & 549,731 & 4.8 & 526 \\
HP (starting pulp) & 82,978 & 232,834 & 367,395 & 2.8 & 656 \\
HP (P4 treated) & 73,417 & 204,945 & 356,168 & 2.8 & 551 \\
HP (P10 treated) & 65,682 & 191,284 & 336,306 & 2.9 & 545 \\
HP (P11 treated) & 70,225 & 169,764 & 292,638 & 2.4 & 504 \\
\hline
\end{tabular}

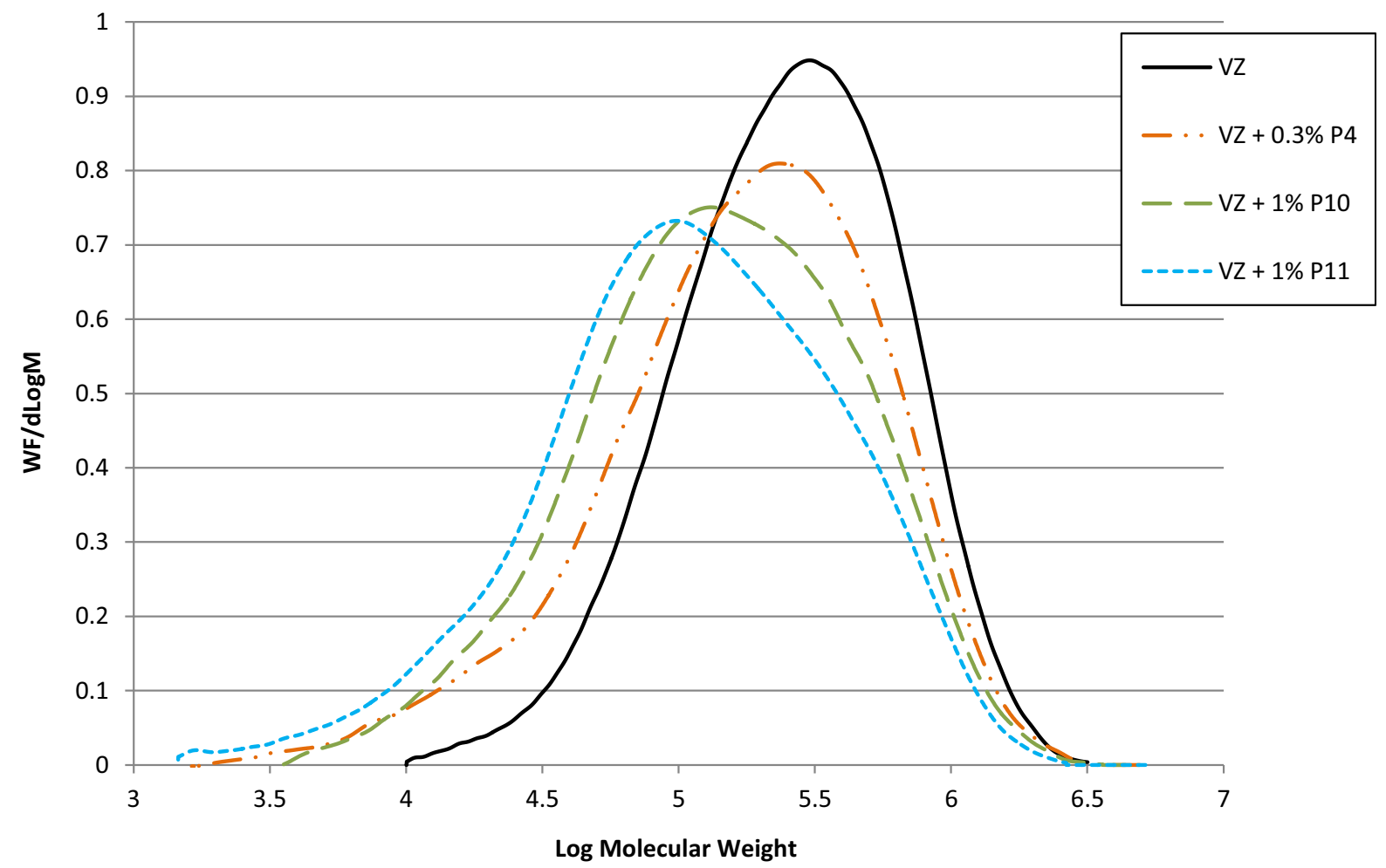

Fig. 5 MWD of starting and enzymatic modified VZ pulp samples

(Fig. 3, right). Because of the high particle content of the $9 \%$ dope from the starting pulp with a large number of particles with high aspect ratio, a particle characterisation with laser diffraction was not possible. In contrast, very small particle contents $(<20 \mathrm{ppm})$ with low particle sizes (up to $51 \mu \mathrm{m}$ in maximum) were detected by laser diffraction at the prepared dopes from enzymatic modified pulp samples.

Laboratory spinning tests using dope sample NH-P 1 from the unmodified pulp showed very unstable spinning behaviour. Alongside many capillary breaks, the spinning pressure increased from 32 to 38 bar already during the short time of the laboratory spinning test of about $30 \mathrm{~min}$. This pressure increase should be caused by accumulation of particles on the safety filter device because of the worse dope quality containing undissolved fibre residuals or rather gel contents. By contrast, the spinning dopes prepared using the enzymatic modified pulp samples could be spun in a very stable manner at this laboratory scale (capillary diameter: $100 \mu \mathrm{m}, 30$ capillaries). The used spinning speed was $30 \mathrm{~m} / \mathrm{min}$. Further applied spinning 
conditions and achieved fibre properties are listed in Table 5.

The rheological properties of the prepared spinning dopes, applying the enzymatic modified NH-P pulp samples, are in a well-suitable area for Lyocell process technology.

The textile physical properties of the prepared fibres were only slightly below the level of conventional Lyocell fibres. It illustrates, that the prepared fibres from paper grade pulps showed slightly increased WRV compared with Lyocell fibres, prepared using typical Lyocell pulps (Michels and Kosan 2006).

The DP degradation between the pulp samples used for dope preparation and the fibres spun thereof, is about $8 \%$ at the modified samples and also at the unmodified sample NH-P 1. However, the evaluation of the MWD of the samples (Fig. 4) indicates that significant amounts of the high molecular chains have not been transferred into the fibres, obviously through filtration of undissolved pulp amounts. On the other hand, some low molecular pulp amounts were separated during the spinning process using the starting pulp, which could be enriched in the spinning bath. The enzymatically modified pulp samples showed already minor low molecular pulp fractions, and the MWD of the pulp and fibre samples showed significantly lower differences than in the case of unmodified pulp. For better overview, Fig. 4 contains exemplary only the results from the P11 modified pulp sample.

First upscaling tests for the enzymatic treatment (1\% P11) of the pulp sample NH-P and following dope preparation were carried out for staple fibre and filament preparation. Both the enzymatic treatment and the dope preparation were carried out firstly with discontinuous batch trials. First calculations from the mass balance of the enzymatic treatment step showed very low pulp losses between 1 and $2 \%$. The preparation of the spinning dopes was possible using dissolution conditions comparable to typical Lyocell pulps. Semi-technical spinning tests $(6 \times 80$ capillaries, $90 \mu \mathrm{m}$ outlet diameter) for investigation of the spinning behaviour and stability as well as the preparation of staple fibres and multifilament yarn were carried out using $12 \%(\mathrm{w} / \mathrm{w})$ cellulose dopes.

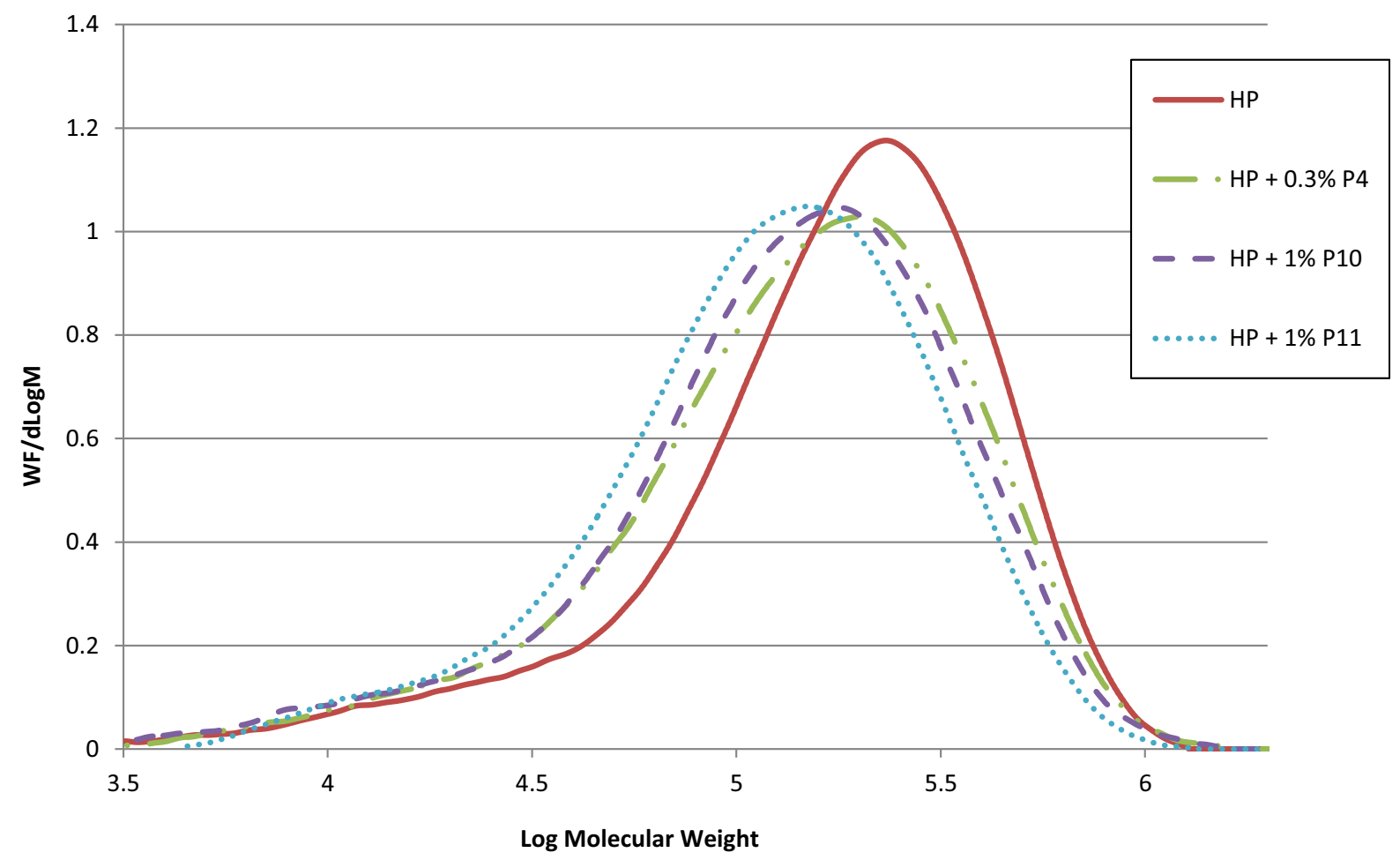

Fig. 6 MWD of starting and enzymatic modified HP pulp samples 
Solvent recycling of the spinning bathes was carried out without significant changes to spinning dopes from usual Lyocell pulps. Further investigations, especially after longer continuous trials, are necessary for further investigations concerning the influence of pulp impurities during continuous processing. The prepared fibre samples showed good textile-physical properties. The results of these tests were discussed in detail in former publication (Kosan and Meister 2018).

\section{Results of enzymatic pulp modification using further pulp samples}

Enzymatic modification procedures using the enzyme samples P4, P10 and P11 were also tested using the pulp samples VZ and HP. Table 6 and Figs. 5, 6 contains an overview with important results of these investigations.

The viscose pulp sample VZ is characterised by high $\alpha$-cellulose content and very narrow MWD. The enzymatic treatment of this pulp sample provided graded Cuoxam-DP values of the modified samples using the enzyme samples P4, P10 and P11. The very narrow MWD of the starting pulp was widened through the enzymatic modification.

The enzymatic modification of the hemp pulp sample HP resulted in reduction of the Cuoxam-DP between 16 and $23 \%$ without significant changing of the polydispersity (Table 6).

The enzymatic activities were different using the substrates VZ and HP pulps with high $\alpha$-cellulose content. P11 performed better than P10 and P4. In contrast, with modified NHP-pulp, pulp modification was almost the same for the three preparations. Endohydrolysis occurred for all substrates. For NHP-pulp, hydrolysis of non- $\alpha$-cellulose may have occurred in addition. In this case the preparations P10 and P4 had the advantage of a broader enzymatic spectrum (Fig. 1a).

\section{Conclusion}

From a collection of cellulolytic industrial preparations of different origins, suitable samples for the enzymatic modification of pulp were identified. Among biochemical tests available, assay of betaglucanase showed some correlation with DP-reduction test. A more specific biochemical assay based on solid substrate would be desirable for molecular approach in further developments. Remarkably, P11 performed best in reduction of polymerization degree and no FPU was detectable in this preparation. In former works, cellulase pre-treatment with high FPU was found to promote cellulose dissolution in NMMO (Meister et al. 1996).

An enzymatic modification using cellulases with adapted enzymatic activities is a suitable approach for adjustment of molecular pulp properties like molecular weight distribution and average degree of polymerisation. Moreover, an improvement of the accessibility and solubility properties of alternative pulp resources for Lyocell application was attainable by enzymatic treatment.

The DP reduction of different tested pulp qualities was detected between 20 and $35 \%$, with regard to the Cuoxam-DP of the non-modified pulp sample. Depending on the used pulp quality, different changes of the molecular weight distribution were detected. The polydispersity of the very broad distributed paper grade pulp NH-P was significant reduced by the tested enzymatic modification. By contrast, the very low polydispersity of the viscose pulp sample VZ was increased by enzymatic treatment for improved spinning stabilities at dry-wet spinning. Furthermore, the tested enzyme samples with adjusted exo- and endoactivities surprisingly effected also a significant improvement of the pulp solubility. Therefore, spinning dopes with very good dissolution behaviour were obtained, even when paper grade pulps with lower contents of $\alpha$-cellulose are used.

The tested modification step should be adaptable in the Lyocell process. The use of such an innovative modification step can significantly extend the raw material base for Lyocell process technology. It could enable cost savings when less expensive cellulose raw materials (paper pulps) are applied, and it may provide also broader options for use of pulps extract from recycled cellulose fabrics or from annual plant fibres next to cotton.

Acknowledgments Open Access funding provided by Projekt DEAL. These works were financially supported by the German Federal Ministry of Economics and Energy (BMWi Nos. MF140191 and EP141226). The authors thank for the granted support. 
Open Access This article is licensed under a Creative Commons Attribution 4.0 International License, which permits use, sharing, adaptation, distribution and reproduction in any medium or format, as long as you give appropriate credit to the original author(s) and the source, provide a link to the Creative Commons licence, and indicate if changes were made. The images or other third party material in this article are included in the article's Creative Commons licence, unless indicated otherwise in a credit line to the material. If material is not included in the article's Creative Commons licence and your intended use is not permitted by statutory regulation or exceeds the permitted use, you will need to obtain permission directly from the copyright holder. To view a copy of this licence, visit http://creativecommons.org/licenses/by/4.0/.

\section{References}

Berthold F, Gustafsson K, Sjöholm E, Lindström M (2001) An Improved Method for the Determination of Softwood Kraft Pulp Molecular Mass Distributions. $11^{\text {th }}$ International Symposium on Wood and Pulping Chemistry Nice France June 11 to 14,2001

Björquist S, Aronsson J, Henriksson G and Persson A (2017) Textile qualities of regenerated cellulose fibers from cotton waste pulp. Textile Research Journal. https://doi.org/10. 1177/0040517517723021

Eichinger D (2012) A Vision of the World of Cellulosic Fibers in 2020. Lenzinger Berichte 90:1-7

Gherzi (2011) The future challenges for cotton availability: chance for Man-made cellulose fibers? Allgemeiner Vliesstoff-Report 2:48

Ghose TK (1987) Measurement of cellulase activities. Pure Appl Chem 59:257-268

Grönqvist S, Kamppuri T, Malonay T, Vehviläinen M, Liitiä T, Suurnäkki A (2015) Enhanced pre-treatment of cellulose pulp prior to dissolution into $\mathrm{NaOH} / \mathrm{ZnO}$. Cellulose 22:3981-3990. https://doi.org/10.1007/s10570-015-07428

Hämmerle FM (2011) The Cellulose Gap (The future of cellulose fibres). Lenzinger Berichte 89:12-21

Harms H (2002) Potentiale einer neuen Fasergeneration. Lenzinger Berichte 81:27-34

Kalt W, Zauner B (2001) Das Lenzing Lyocell Projekt - Start in ein neues Zeitalter der großtechnischen Zellulosefaserherstellung in Europa. Lenzinger Berichte 80:10-12

Klemm D, Philipp B, Heinze T, Heinze U, Wagenknecht W (1998) Determination of the DP of cellulose in cuam solution. Comprehensive cellulose chemistry, Wiley-VCH $1: 234-235$

König J, Grasser R, Pikor H, Vogel K (2002) Determination of xylase, $\beta$-glucanase, and cellulase activity. Anal. Bioanal. Chem. 374:80-87
Kosan B, Meister F (2018) Possibilities for Raw Material Base Expansion for Lyocell Applications by Enzymatic Pulp Treatment. Lenzinger Berichte 94:123-130

Kosan B, Michels C (1999) Particle analysis by laser diffraction - application and restrictions in the Lyocell process. Chemical Fibers International 49:50-54

Kosan B, Michels C, Meister F (2008) Dissolution and forming of cellulose with ionic liquids. Cellulose 15:59-66

Kosan B, Schwikal K, Meister F (2012) Effects of pre-treatment and dissolution conditions for improved solution and processing properties of cellulose in ionic liquids. Lenzinger Berichte 90:76-84

Kostylev M, Wilson D (2012) Synergistic interactions in cellulose hydrolysis. Biofuels 3:61-70

Meister F, Kosan B (2015) A tool box for characterization of pulps and cellulose dopes in Lyocell technology. Nordic Pulp \& Paper Research Journal 30:112-120

Meister F, Michels C, Kramer H (1996) Regenerated Cellulose Moulding and Process for Producing it: WO 1996014451

Michels C, Kosan B (2003) Contribution to dissolution state of cellulose in aqueous amine oxide characterized by optical and rheological methods. Lenzinger Berichte 82:128-135

Michels C, Kosan B (2006) Beitrag zur Struktur von Lyocellfasern, ersponnen aus Aminoxidhydraten bzw. ionischen Flüssigkeiten. Lenzinger Berichte 86:144-153

Östberg L, Germgard U (2013) Some aspects on the activation of dissolving pulps and the influence on the reactivity in a following viscose stage. Cellulose Chem. Technol. 47:165-169

Paulitz J, Sigmund I, Kosan B, Meister F (2017) Lyocell fibers for textile processing derived from organically grown hemp. Procedia Engineering 200:260-268

Suurnäkki A, Tenkanen M, Siika-Aho M, Niku-Paavola ML, Viikari L, Buchert J (2000) Trichoderma reesei cellulases and their core domains in the hydrolysis and modification of chemical pulp. Cellulose 7:189-209

Vehviläinen M, Kamppuri T, Grönqvist S, Rissanen S, Maloney T, Honkanen M, Nousiainen P (2015) Dissolution of enzyme-treated cellulose using freezing-thawing method and the properties of fibres regenerated from the solution. Cellulose 22:1653-1674. https://doi.org/10.1007/s10570015-0632-0

Vermaas JV, Crowley MF, Beckham GT, Payne CM (2015) Effects of Lytic Polysaccharide Monooxygenase Oxidation on Cellulose Structure and Binding of Oxidized Cellulose Oligomers to Cellulases. Journal of Physical Chemistry B 119:6129-6143

Wollenschlaeger U (2017) Fasermarkt überschreitet 100 Millionen Tonnen-Grenze, TextilWirtschaft https://www. textilwirtschaft.de/business/unternehmen/TextilfasernFasermarkt-ueberschreitet-100-Millionen-TonnenGrenze-204514

Publisher's Note Springer Nature remains neutral with regard to jurisdictional claims in published maps and institutional affiliations. 